International Journal of Behavioral Research \& Psychology (IJBRP)

ISSN 2332-3000

\title{
"Locus of Control, Birth Order and Residence as predictors of General Wellbeing with special reference to Tripura"
}

Research Article

Mukherjee $\mathrm{H}^{*}$, Mukherjee $\mathrm{P}$

Assistant Professor, Faculty of Education, The ICFAI University Tripura, India.

\begin{abstract}
This study focuses on the Locus of Control, Birth Order and Residence as predictors of General Wellbeing with special reference to Tripura by taking 400 degree level students from different degree colleges and universities of Tripura state. Review of literature demonstrates that different factors associated with general wellbeing operate differently in different cultures and races and since there is dearth of such systematic study under Indian set up, it is appropriate to investigate empirically that whether or not locus of control, birth order and residence independently or in interaction with each other are accountable for differences in General Wellbeing among students. The following conclusions were drawn on the basis of analysis of data like Locus of control significantly influences general wellbeing of students, internally controlled students were found superior on general wellbeing than externally controlled students. Birth order of the students seems to have significant influence on general wellbeing. First born students were found higher on general wellbeing than later born students. Residence does not account for substantial amount of variance on general wellbeing of students. Urban or rural students have yielded equal outcome on the scores of general wellbeing. Locus of control and birth order appears to interact to yield significant results on general wellbeing. Locus of control and residence and birth order and residence of the students do not appears to interact to yield significant results on general wellbeing. Locus of control, birth order and residence of the students do not appears to interact with reference to general wellbeing of the students of Tripura in particular.
\end{abstract}

Keywords: Locus of Control; General Wellbeing.

\section{*Corresponding Author:}

Hillol Mukherjee,

Assistant Professor, Faculty of Education, The ICFAI University Tripura, India.

Tel: +1(248)705-3798

E-mail: hillol.agartala@gmail.com

Received: May 07, 2014

Accepted: June 18, 2014

Published: June 25, 2014

Citation: Mukherjee $\mathrm{H}^{*}$, Mukherjee P (2014) "Locus of Control, Birth Order and Residence as predictors of General Wellbeing with special reference to Tripura". . Int J Behav Res Psychol. 2(5), 53-58. doi: http:// dx.doi.org/10.19070/2332-3000-1400010

Copyright: Hillol Mukherjee (C) 2014. This is an open-access article distributed under the terms of the Creative Commons Attribution License, which permits unrestricted use, distribution and reproduction in any medium, provided the original author and source are credited.

\section{Introduction}

Identification of possible correlates of general wellbeing provides a clue regarding the antecedents/determinants of general wellbeing. Perhaps the most consistent and reliable correlates of wellbeing pertain to central role played by people's goals, coping efforts, and dispositions (Diener, Suh, Lucas and Smith, 1999). The present study empirically investigates the possible effect of locus of control, birth order and residence on general wellbeing. Wellbeing is the degree to which an individual judges the overall quality of his or her life as a whole in a favourable way (Veenhoven, 1984).

A locus of control is a person's belief about how much power one has over the events in one's life. According to psychologist Julian Rotter, who formulated the concept in the 1950s, the locus of control is a dimension of personality; it helps explain one's traits and behavior. An internal locus of control is the belief that the course of one's life is largely up to oneself. Those with an external locus of control regard the events in their lives as occurring regardless of their own efforts. People who have an internal locus of control tend to be less influenced by others, more politically active, and more motivated to achieve. Many researchers believe an internal locus of control is more healthful than an external one.

Empirical finding have shown that internals are more cognitively efficient, more alert to the potential meaning of their experiences and less easily coerced by environmental forces. This suggests the importance that an internal locus of control has for effective coping behaviour. If a person is able to quickly assess the options available to him in a challenging situation, he should be able to cope more effective than if he were less absolute about his choices; and if he believed that he was able to effectively act in his own behalf, even consequences would have a less debilitating effect upon him. There fore locus of control may have an impact on wellbeing of the human race.

Different factors associated with general wellbeing operate differently in different cultures and races and since there is dearth of such systematic study under Indian set up, it is appropriate to investigate empirically that whether or not locus of control, birth order and residence independently or in interaction with each other are accountable for differences in general wellbeing among students.Verma and Verma (1989) are of the view that general wellbeing is "the subjective feeling of contentment, happiness, satisfaction with life's experience and one's role in the world of work, sense of achievement, utility, belongingness and no distress, dissatisfaction or worry etc". 
A study by Lee KH, Yoon DP.2001 explores factors that influence the general well-being (anxiety, depression, positive well-being, self-control, vitality, and general health) of low-income Korean immigrant elders by interviewing 206 older adults living in Los Angeles County and Orange County, California. Ordinary least squares regression results reveal that lack of English proficiency and longer residence in the United States were significant predictors of higher anxiety, higher depression, lower self-control, lower vitality, and lower general health among Korean immigrant elders. Losing a spouse was a significantly negative factor in vitality. Financial problems were significantly associated with lower positive well-being. Social environment and social support were the significant factors in lower anxiety, lower depression, higher positive well-being, higher self-control, and higher vitality. The findings of this study show that low-income Korean immigrant elders are at high risk for psychological and physical health problems influenced by difficulties with the acculturation or adjustment and socioeconomic stress of living in a new society. The study discusses essential implications for culturally competent social work practice among low-income Korean immigrant elders. This led the researcher to consider residence as another variable to study as a predictor of wellbeing.

Different factors are associated with general wellbeing that operate differently in different cultures and races and since there is dearth of such systematic study under Indian set up, it is appropriate to investigate empirically that whether or not locus of control, birth order and residence independently or in interaction with each other are accountable for differences in Wellbeing among students.

\section{Objectives of the Study}

The following objectives were set forth in the present investigation:-

1. To study the impact of locus of control, birth order and residence on general wellbeing of students.

2. To investigate the interaction effects of locus of control and birth order, locus of control and residence and birth order and residence on general wellbeing of students.

3. To study the interaction effects of locus of control, birth order and residence on general wellbeing of students.

4. To study the impact of locus of control, birth order and residence on general wellbeing of students.

5. To investigate the interaction effects of locus of control and birth order, locus of control and residence and birth order and residence on general wellbeing of students.

6. To study the interaction effects of locus of control, birth order and residence on general wellbeing of students.

\section{Hypotheses}

The specific research hypotheses have been detailed in line with the objectives mentioned just above. The following hypotheses were framed for verification in the present study:-

1. There would be a significant difference in internally controlled and externally controlled students on general wellbeing.

2. There would be a significant difference on general wellbeing among first born and later born students.

3. There would be a significant difference on general wellbeing among urban and rural students.

4. There would be a significant interaction effect of locus of control and birth order on general wellbeing of students.

5. There would be a significant interaction effect of locus of control and residence on general wellbeing of students.

6. There would be a significant interaction effect of birth order and residence on general wellbeing of students.

7. There would be a significant interaction effect of locus of control, birth order and residence on general wellbeing of students.

\section{Sample}

All regular students studying in graduation and post graduation level of 4 different colleges and 2 different universities of Tripura located in Agartala West district are considered in this present investigation. The sample for the present study consists of $400 \mathrm{stu}-$ dents approx. It included both male and female students $(18-24)$ of Arts, Maths, languages, Science and Commerce Streams. Locus of control, birth order and residence were independent variables and general wellbeing was the dependent variable.

\section{Procedure}

PGI General Wellbeing Measure (Verma, Mahajan and Verma, 1989) and Levenson's Locus of Control Scale were administered to the university and college students in their class room settings. Before administering the tests, the objectives of the study were explained to them. They were requested to extend their co-operation by responding to each item honestly, sincerely and truthfully. Thereafter, procedure for answering each item was explained. On completion, the tests were collected and scored as per instructions given in the manual. The obtained data were analyzed using appropriate statistical techniques. The results were interpreted in line with the objectives stated.

\section{Statistical Treatment}

To study the main and interaction effect of locus of control, birth order and residence on general wellbeing of University students, a 2 × 2 × 2 factorial design was employed. In this design each of the three independent variables were varied at two levels. Residence and birth order are dichotomous variables, where as locus of control was classified into two groups (internal and external locus of control) following the opposite extreme group technique of $27 \%$ upper and $27 \%$ lower as cutting points of the distribution of LOC scores. Locus of control was designated as ' $\mathrm{A}$ ' factor, birth order as ' $\mathrm{B}$ ' factor and residence as 'C' factor. Internal locus of control, first born and urban University students were designated as A2, B2 and C2 respectively. Subjects were thus kept in eight cells. 15 Subjects were assigned to each cell to have equal size of $\mathrm{N}$ in each group.

\section{Result \& Discussion}

The number of respondents of different possible combinations of the three independent variables namely locus of control(A), birth order(B) and residence (C) along with mean scores on general wellbeing are presented in Table 1.

As per factorial design of $2 \times 2 \times 2$, three way analysis of variance was performed on the scores of general wellbeing to ascertain the main and interaction effects of three independent variables namely locus of control, birth order and residence. 
Table 1. Number of respondents and mean general wellbeing scores of different combination of groups.

\begin{tabular}{|c|l|l|}
\hline Groups & No & Mean \\
\hline A1B1C1 & 15 & 14.26 \\
\hline A1B1C2 & 15 & 15.46 \\
\hline A1B2C1 & 15 & 14.73 \\
\hline A1B2C2 & 15 & 12.40 \\
\hline A2B1C1 & 15 & 11.46 \\
\hline A2B1C2 & 15 & 10.93 \\
\hline A2B2C1 & 15 & 7.40 \\
\hline A2B2C2 & 15 & 7.40 \\
\hline
\end{tabular}

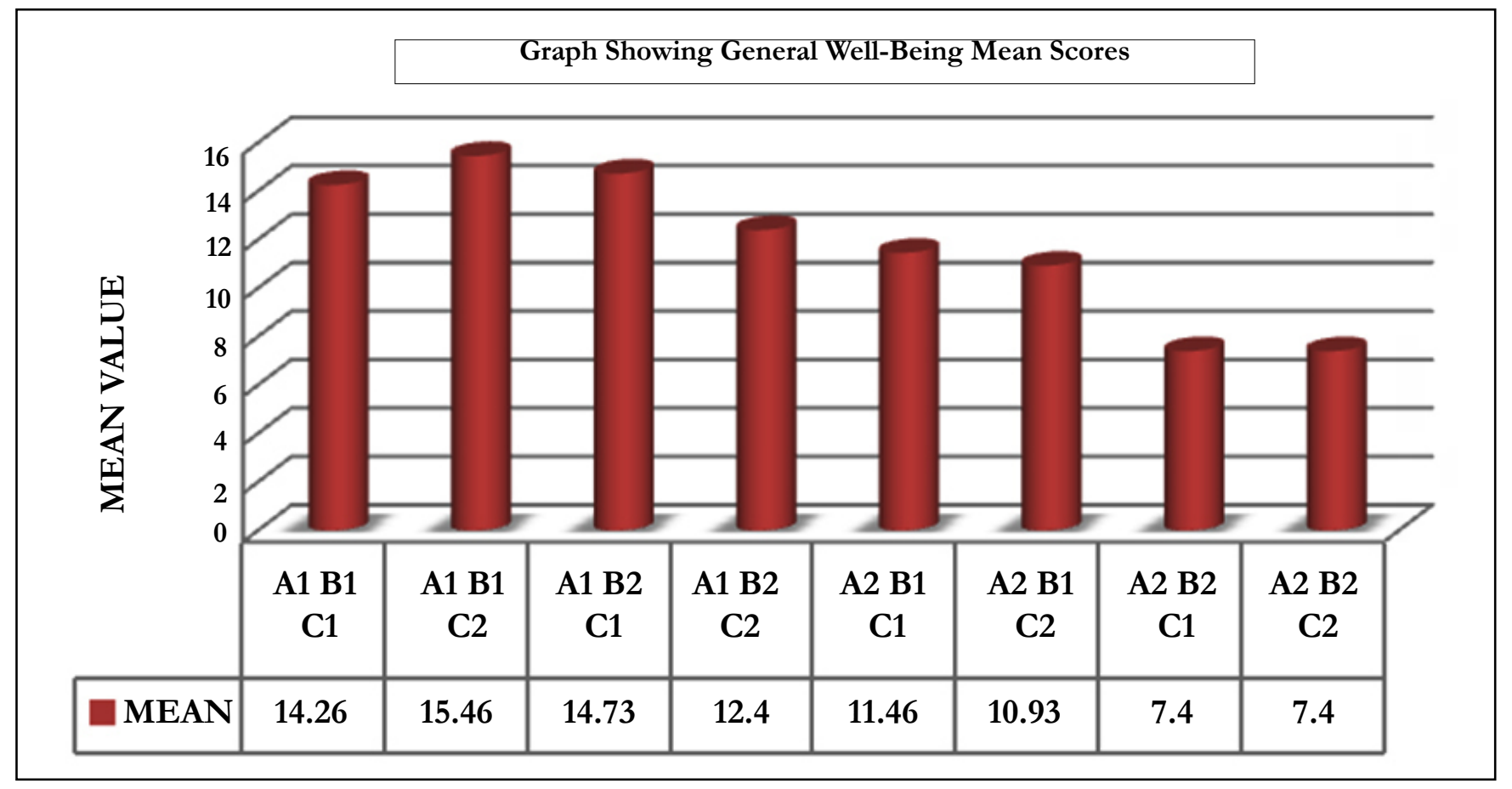

Table 2. Summary of three ways ANOVA for wellbeing $(2 \times 2 \times 2)$ factorial design.

\begin{tabular}{|l|l|l|l|l|}
\hline Source of Variation & Sum of Squares & df & Mean Square & F-ratio \\
\hline Main effects & & & & \\
\hline Locus of Control (A) & 752.208 & 1 & 752.208 & $68.25^{*}$ \\
\hline Birth Order (B) & 195.074 & 1 & 195.074 & $17.70^{*}$ \\
\hline Residence ( C) & 5.208 & 1 & 5.208 & $0.472^{*}$ \\
\hline Two way interactions & & & & $4.245^{* *}$ \\
\hline $\begin{array}{l}\text { Locus of Control X Birth } \\
\text { Order(AXB) }\end{array}$ & 46.875 & 1 & 46.875 & $0.061^{*}$ \\
\hline $\begin{array}{l}\text { Locus of Control X } \\
\text { Residence(AXC) }\end{array}$ & 0.675 & 1 & 0.675 & 1.53 \\
\hline $\begin{array}{l}\text { Birth Order X } \\
\text { Residence(BXC) }\end{array}$ & 16.87 & 1 & 16.87 & \\
\hline Three way interaction & & 1 & 4.012 & 0.364 \\
\hline $\begin{array}{l}\text { Locus of Control X Birth } \\
\text { Order } \\
\text { X Residence (A X B X C) }\end{array}$ & 4.012 & 112 & 11.02 & 18.9 \\
\hline SSw & 1235.07 & 119 & & \\
\hline Tss & 2255,99 & & & \\
\hline
\end{tabular}

$* \mathrm{P}<0.01 ; * * \mathrm{P}<.05$. 
Table 3. Means and Mean differences of students indicating A X B interaction

\begin{tabular}{|l|l|l|l|}
\hline S1. No. & Group & Mean & Mean Difference \\
\hline I & A1B1 & 14.86 & $\begin{array}{l}\text { I-II }=14.86-13.56=1.30 \\
\text { I-III=14.86-11.20=3.66 }\end{array}$ \\
\hline II & A2B2 & 13.56 & I-IV=14.86-7.40=7.46 \\
\hline III & A2B1 & 11.20 & $\begin{array}{l}\text { II-III }=13.56-11.20=2.36 \\
\text { II-IV=13.56-7.40=6.16 }\end{array}$ \\
\hline IV & A2B2 & 7.40 & III-IV=11.20-7.40=3.80 \\
\hline
\end{tabular}

Means of students indicating AxB interaction

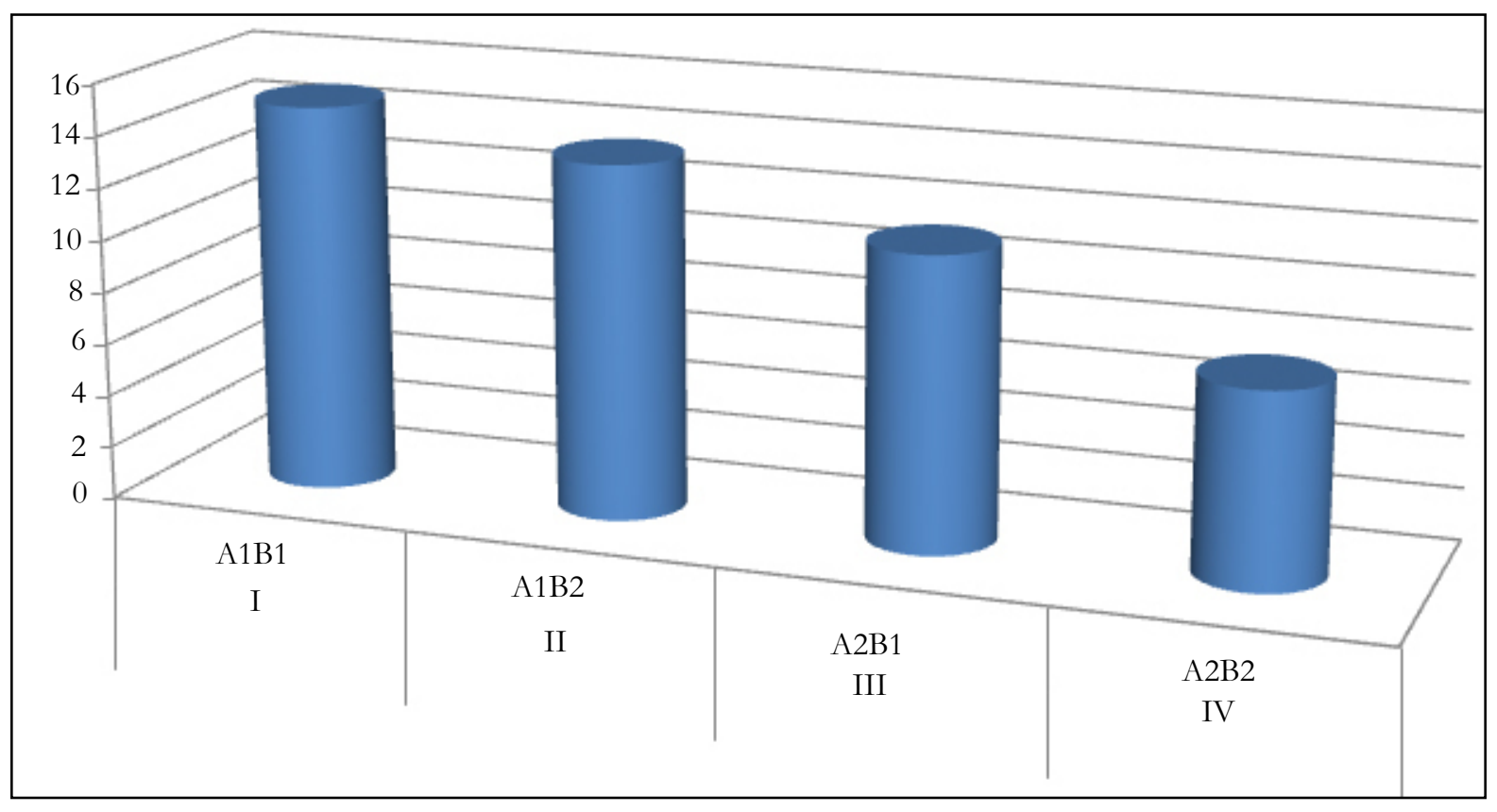

The ' $\mathrm{F}$ ' ratios computed for different main effects and interaction effects have been shown in Table 2.

Results Table 2 depicts that the obtained value of $\mathrm{F}$ (68.25) is highly significant. The results indicate that locus of control has significant main effects on general wellbeing of students. It may be concluded that both the groups (A1 and A2) differed significantly. Further, the mean score of internally controlled group it came out to be 14.21 and for externally controlled group it came out to be 9.3. Obviously, the mean difference was in favour of internally controlled students. Thus, it can be interpreted that internally controlled students are higher on general wellbeing than their counterpart externally controlled students. Hence the hypothesis that, "There will be significant difference in externally controlled and internally controlled students on general wellbeing has been accepted in this study.

F-ratio for birth order was found out to be 17.70 which is significant at .01 level of confidence. It implies that first born group of students differs significantly than later born group of students. At a glance the mean scores indicates that the first born group of students $(\mathrm{M}=13.03)$ is higher in comparison to later born $(M=10.48)$. Obviously the first born groups of students are higher on wellbeing than later born group of students. Hence, the research hypothesis stating that, "There will be significant difference on general wellbeing among first born and later born students" stands accepted.

The main effect of residence was analyzed over two levels of
Locus of Control (A) and Birth Order (B). Table 2 depicts that F-ratio for residence came out to be 0.472 which is not significant. It indicates that the main effect of residence was not significant. Thus it can be concluded that as for as general wellbeing is concerned residence do not play a significant role. Hence, the research hypothesis stating that, "There will be significant difference on general being among urban and rural students" stands rejected.

On the perusal of Table 2, it is clear that F-ratio for A X B interaction came out to be 4.245 which is significant at 0.5 level. In other words difference between the mean of A1 and A2, (Internally controlled and externally controlled) for first born group of students (B1) is significantly different from the difference between the mean of A1 and A2, (Internally controlled and externally controlled) for later born group of students (B2). Thus it can be concluded that A X B interaction is significant. Hence, the hypothesis that, "There will be significant interaction effects of locus of control and birth order on general wellbeing of students" has been accepted in this study.

The mean scores of A X B interaction as shown in Table 3 indicates that internally controlled and first born students surpassed all other groups of students on general wellbeing $(M=14.86)$. Externally controlled and later born students were found lowest among the groups $(M=7.40)$.

A scrutiny of Table 2 indicates that F-ratio for A X C interaction came out to be 0.061 which is not significant at any level. As such the difference between means of internally controlled (A1) and 
externally controlled (A2) for urban group of students (C1) is not different from the difference between the mean of internally controlled (A1) and externally controlled (A2) for rural group of students (C2). Thus, the research hypothesis that," There will be significant interaction effect of locus of control and residence on general wellbeing of students" has been rejected in this study.

Table 2 indicates that F-ratio for $\mathrm{B} \mathrm{X} \mathrm{C}$ interaction is 1.53 which is not significant at any level. It indicates that difference between the means of first born (B1) and later born (B2) for urban students (C1) is not significantly different from the difference between the means of first born (B1) and later born (B2) for rural students (C2). Thus, the research hypothesis stating that, "There will be significant interaction effect of birth order and residence on general wellbeing of students" has been rejected in the present study.

The higher order i.e. three factor interaction effects of Locus of control (A) X Birth order (B) X Residence (C) was analyzed using three way analysis of variance. The Table 2 depicts that ' $F$ ' ratio for three way analysis of variance came out to be 0.364 which is not significant at any level. Thus, the research hypothesis that, "There will be significant interaction effect of locus of control, birth order and residence on general wellbeing of students" stands rejected.

The research on general wellbeing has become an area of interest among researchers and practitioners in many fields during last few decades. To date, researchers have identified numerous personal background characteristics that appear to be associated with general wellbeing. Review of literature on wellbeing suggests that the research on locus of control and birth order in relation to wellbeing has been scanty and tardy. As reported earlier the present study was carried out on 400 post graduate students of different Colleges and Universities, Agt using locus of control, birth order and residence as independent variables and general wellbeing as dependent variable. The result shows that internally controlled group of students are significantly higher on general wellbeing than externally controlled group of students. It may be because people high on internal locus of control are more active in attempting to manipulate their environment, while extends are passive in manipulating their environment (Stadford and Govier, 1991 cited in Kulshrestha and Sen, 2006). Internals, believe, they control their own destiny. Therefore, they act to take control of events in contrast to individuals with external locus of control. Individuals with external locus of control feel powerless in terms of controlling their success or failure, Kulshrestha and Sen, (2006), observed that those with internal locus of control is more positive behaviour and outcomes then holding on external locus of control with the results internals have definite goal in sustaining life. The findings of the present study are also indirectly supported by the studies of Epstein and Mocpartland (1977) in which, they demonstrated that students perceptions of an internal locus of control experienced greater depression leading to low wellbeing. Kulshrestha and Sen (2006) also found that internals are significantly better on subjective wellbeing than externals.

The second main effect related to birth order was found significant revealing that first born and later born group of students differed significantly. First born group of students was found higher on general wellbeing in comparison to later born students. Although, the research related to the effect of birth order on general wellbeing is rare and scanty, yet some indirect support may be provided by the studies conducted on this field.
Price (1969) reported that first borns are less found of Cuddling, are easier to train work harder at school and set higher standards for them. Further more, they are more serious, methodical, law abiding, tidy, less impulsive, given more responsibility at school, more nervous and less happy. The study reported above depict that first borns are significantly superior on some of the components on general wellbeing i.e. pleasant affect, life satisfaction and domain satisfaction. Farly, Smart and Brithan (1976) found birth order to be significant factor in academic achievement and attainment of eminence. Schulman and Mosak (1977) in summarizing Adler's description of the effect of birth order have said, "Birth order is not absolute determinant, only on influence. The reaction of parents to child is at least as important.

The third main effect of residence was found non-significant. The mean scores of both the groups were found identical, meaning there by that general wellbeing has nothing to do with urban or rural background of students. It may be because due to modernization and globalization that the life styles of rural population has changed and have come at par with the urban population. There is thus, little difference in the environment of urban and rural areas which resulted in non-significant difference in wellbeing.

The interaction effects of locus of control, birth order and residence did not emerge as significant meaning thereby that the interaction effect is redundant. The three factor interaction effects revealed that interaction between locus of control, Birth order and residence is not significantly related to general wellbeing. The result need to be probed further by employing different samples and tools. However, the results reported above do not get empirical support because similar research evidences are locking on general wellbeing.

\section{Conclusion}

The following conclusions were drawn on the basis of analysis of data:

1. Locus of control significantly influences general wellbeing of students. Internally controlled students were found superior on general wellbeing than externally controlled students.

2. Birth order of the students seems to have significant influence on general wellbeing. First born students were found higher on general wellbeing than later born students.

3. Residence does not account for substantial amount of variance on general wellbeing of students. Urban or rural students have yielded equal outcome on the scores of general wellbeing.

4. Locus of control and birth order appears to interact to yield significant results on general wellbeing.

5. Locus of control and residence and birth order and residence of the students do not appears to interact to yield significant results on general wellbeing.

6. Locus of control, birth order and residence of the students do not appears to interact with reference to general wellbeing.

\section{References}

[1] Adler.A. (1928). Understanding Human Behaviour. George Allen and Unwin. London.

[2] Asthana, A. \& Singh, P. K. (2004). Challenges in Educating Disadvantaged Children. Indian Journal of Community Psychology; 1: 236-242.

[3] Benass V. S, Sweeny P. D. \& Dufour F. L (1988) Is There a Relation between 
Locus of Control Orientation and Depression?J Abnorm Psychol 97(3):35767.

[4] Bradburn M.M, Caprovitz D. (1965) Reports of Happiness. (3), Aldine Chicago.

[5] Campbell A. (1981). The Sense of Wellbeing in America: Recent Patterns and Trends. Newyork: Mc Graw Hill.

[6] Carlise - Frank P (1991) Examining Personal Control Beliefs as mediating variable in the Health-Damaging Behaviour of Substance Use: An Alternative Approach. The Journal of Psychology 125:381-397.

[7] Clark AH, Oswald AJ (1994) Unhappiness and Unemployment. Economic Journal 104:648-659.

[8] Davies M, Stankov L \& Roberts R.D (1998) Emotional Intelligence in search of an Elusive Construct. Journal of Personality and Social Psychology 75: $989-1015$.

[9] Diener E, Suh M, Locus RE, Smith L (1999) Subjective Wellbeing: Three Decades of progress. Psychological Bulletin, 125:276-302.

[10] Diener E, Suh M (1997) Measuring Quality of Life: Economic, Social and Subjective indicators. Social Indicators Research 40:189 - 216.

[11] Diener E (1993) The Relationship between income and Subjective Wellbeing: Relative or Absolute? Social Indicators Research 28:195-223.

[12] Eas Varadoss V, Samadhi D, Rekha B (2005) Effect of Maternal Employment Birth order or Carrier Making Self Efficacy among Adolescents. Indian Journal of Applied Psychology. 42

[13] Elison C G (1991) Religious Involvement and Subjective Wellbeing. Journal of Health and Social Behaviour 32:80-89.

[14] Faizo A Z (1977) A Concurrent Validation Study of NCHS General Wellbeing Schedule, Department of Health, Education \& Welfare.

[15] Farley FH, Smart K.L, Brithain CV (1976) Academic Achievement, Motivation and Birth order in Adults. Journal of Social Psychology 98:283-284.

[16] Gates L, Lineberger M.R, Crockett J, Hubbard J (1988) Birth order and its Relationship to Depression, Anxiety and Self Concept Test Scores in Children. Journal of Genetic Psychology 149:29-34.

[17] Hans T (2000) A meta-analysis of the effects of adventure programming on locus of control. Journal of Contemporary Psychotherapy 30(1):33-60.

[18] Haring M.J, Stock W.A, Okum M.A (1984) A Research Synthesis of Gender and Social Class as Correlates of Subjective Wellbeing. Human Relations 37:645-657.

[19] Hattie JA, Marsh HW, Neill JT, Richards GE (1997) Adventure Education and Outward Bound: Out-of-class experiences that have a lasting effect.Review of Educational Research 67:43-87.

[20] Kalia A.K, Devi S, Sheoran A (2001) Birth Order and Depression among School Going Children. Prachi Journal of Psycho-cultural Dimensions 17:149-152.
[21] Kulshrestha U, Sen C (2006) Subjective Wellbeing in Relation to Emotional Intelligence and Locus of Control among Executives. Journal of the Indian Academy of Applied Psychology 32: 129-134.

[22] Lachman M. E, Weaver S.L (1998) The Sense of Control as a Moderator of Social class differences in Health and Wellbeing. Journal of Personality and Social Psychology 74: 763-773.

[23] Lucas R. E, Diener E, Grob A, Such E. M, Shao L (1998) Cross Cultural Evidence of fundamental Features of Extraversion: The Case against Sociability. In: E.Diener, H.E. Suh, E. R.Locus, \& L.H. Smith, (Eds.). Subjective Wellbeing: Three Decades of progress. Psychological Bulletin 125: 276- 302.

[24] Mamlin N, Harris K.R, Case LP (2001) A Methodological Analysis of Research on Locus of Control and Learning Disabilities: Rethinking a Common Assumption.Journal of Special Education 34(4):214-25.

[25] Marsh H. W, Richards G. E (1986) The Rotter Locus of Control Scale: The comparison of alternative response formats and implications for reliability, validity and dimensionality. Journal of Research in Personality 20:509-558.

[26] Mastekaasa A (1995) Age Variations in the Suicide rates and Self Equated Subjective Wellbeing of Married and Never Married Persons. Journal of Community and Applied Social Psychology 5:21-39.

[27] Price J (1969) Personality Differences within Families: Comparison of Adult Brothers and Sisters. Journal of Biosocial Science 1:177-205.

[28] Putter P (2003) The Effects of Birth Order on Depressive Symptoms.

[29] Rotter J (1966) Generalized expectancies for internal versus external control of reinforcements. Psychological Monographs 80: 609.

[30] Schulman B H, Masak H.H (1977) Birth Order and Position: Two Adlerian Views. Journal of Individual Psychology 33:114-121.

[31] Sharma A, Sharma N. R, Yadava A (2005) A Critical Review of Wellbeing Measures. In A. Dalal and S. Ray (Eds.) Social Dimension of Health, New Delhi: Rawat Publication 37-52

[32] Singh S, Singh R (2003) Construct Validation of PGI Wellbeing, in Work Setup. Journal of Indian Academy of Applied Psychology 29:53-60.

[33] Stones M. J, Kozma A (1986) Happy are They who are happy...A test between to causal Models of Happiness and its Correlates, Experimental Aging Research 12:23-29.

[34] Sulloway FJ (1997) Born to Rebel, Birth Order, Family Dynamics and Creative Lives, Pantheon Books, Newyork.

[35] Verma R, hawan N (2005) Socialization, Personal Control and Psychosocial Competence in Relation to Subjective Wellbeing of Educated Indian Women.

[36] Verma S.K, Verma A (1989) Manual for PGI General Wellbeing Measure, Ankur Psychological Agency, lucknow.

[37] Verma A, Mahajan A, Verma, S (1989) A Correlation Study of Two Wellbeing Scales. Journal of Personality and clinical Studies 5:93-95. 